\title{
Bagunça: casamentos e sexualidade em tensão entre indígenas kanhgág
}

\author{
Lucas Cimbaluk ${ }^{1}$ \\ Resumo \\ ${ }^{1}$ Instituto do Patrimônio Histórico e Artístico Nacional, Florianópolis, SC, Brasil
}

Este artigo tem como objetivo explorar alguns aspectos da sexualidade kanhgág a partir do que se chama de bagunça, ou bagunçar, referindo-se aos comportamentos sexuais vistos por certos indígenas como desregrados especialmente ao falar de indígenas mais jovens na contemporaneidade. Esta caracterização permite analisar tensões relativas à monogamia colocada a partir das transformações do grupo após o contato. Contrasto a isso posições ágamas, com o celibato ou uma maior liberalidade sexual. Essas situações representariam alternativas, temporárias ou mais permanentes, diante de certas noções do casamento e da monogamia. A partir dessas situações, procuro estabelecer comparações com outros estudos entre povos Jê-Bororo e outras referências sobre o grupo étnico específico. Faço uma leitura de transformações históricas kanhgág e analiso a bagunça como uma espécie de rito de passagem que precede a vida adulta e como contraefetuação da monogamia e exclusividade sexual. O artigo tem como base etnográfica trabalho de campo realizado pelo autor em aldeias kanhgág localizadas no Norte do Estado do Paraná, Região Sul do Brasil, na região da bacia do rio Tibagi.

Palavras-chave: Sexualidade Indígena. Casamento Indígena. Kaingang.

\section{Bagunça: marriages and sexuality in tension among kanhgág Indians}

\begin{abstract}
This article aims to present some aspects of kanhgág sexuality, addressing what is called bagunça, or bagunçar, referring behaviors that are seen by some Indians as unruled, especially when talking about younger people in contemporary times. This characterization allows to analyze tensions related to the monogamy, derived from the transformations of the group after contact. In contrast, are presented some non-gamic positions, with celibacy or greater sexual liberty. They represent temporary or more permanent alternatives to notions of marriage and monogamy. From these situations, some comparisons are made with studies of other Jê-Bororo groups and previous references of the specific ethnic group. I read some kanhgág historical transformations and analyze the bagunça as a kind of ritual of passage that precedes the adult life and as a conter-efectuation of monogamy and sexual exclusivity. The article has as ethnographic base the field work realized by the author on kanhgág villages located in the north of the state of Paraná, southern Brazil, in the region of the Tibagi river basin.
\end{abstract}

Keywords: Indigenous Sexuality. Indigenous Marriage. Kaingang. 


\section{Introdução}

Teste artigo farei uma descrição de alguns aspectos da sexualidade e do casamento kanhgág ${ }^{1}$ que pude perceber durante meu trabalho de campo realizado entre os anos de 2012 e 2015 em Terras Indígenas (TI) localizadas no Norte do Estado do Paraná em minhas pesquisas de mestrado e doutorado. Seguindo uma descrição mais ampliada das formas de casamento e das tensões colocadas em relação a comportamentos que desafiam noções de monogamia. Trata-se de um esforço de dar conta de situações que chamaram minha atenção pela convivência nas aldeias relacionando-se a temáticas que desenvolvi em trabalhos anteriores e a discussões feitas a partir de outros povos, em especial povos Jê. Abordo o tema tendo atentado a ele por ser um dos pontos centrais da sociabilidade e dos conflitos nas aldeias. É importante destacar que realizei meu trabalho sobretudo entre homens de meia idade ou mais idosos, o que de certa maneira orienta as possibilidades de minhas considerações, que se dão a partir de fora do que se chama de bagunça ou de bagunçar.

O contexto indígena na região da bacia do Tibagi envolve diversas Terras Indígenas interligadas entre si por redes de parentesco e de história que têm composições étnicas diferenciadas. A TI Apucarana, a TI Mococa e a TI Queimadas têm predominância absoluta Kaingang; as TIs Barão de Antonina e São Jerônimo, do outro lado do rio Tibagi, têm população principalmente Guarani Ñandeva e Kaingang, além de famílias Xetá na última. Há poucos indivíduos ou famílias de outras etnias além dessas, vindos, por algum motivo de outras partes do Brasil. Em termos populacionais, a maior dessas Terras Indígenas, a TI Apucarana, é morada de mais de um milhar e meio de habitantes, divididos em aldeias bastante próximas entre si. Nos outros casos, há uma concentração da população em uma aldeia em cada TI, com números que vão de cerca de 150 até pouco mais de 600 pessoas. Apesar da diversidade étnica nas TIs, me restringirei à análise do caso Kaingang² ${ }^{2}$ com o qual trabalhei de forma mais aprofundada.

As aldeias representam certa concentração da população em uma localidade. Apesar de sua pouca estrutura, contam com escolas, em alguns casos postos de saúde em seu interior, além de alguns outros espaços e serviços públicos. As casas são dispostas em ruas, com as áreas agrícolas em seu entorno ou periferia e regiões de mata mais afastadas

\footnotetext{
Utilizo a grafia kanhgág, que é a que vem sendo adotada contemporaneamente por alguns de meus interlocutores, em vez da mais usual no português kaingang. Utilizo a substantivação Kaingang para tratar comparativamente com a bibliografia mencionada em termos de caracterização de grupo étnico.

2 Os Kaingang são um grupo étnico classificado no tronco linguístico Jê, compondo, com os Xokleng, os chamados Jê meridionais. Os Kaingang estão presentes em toda a Região Sul do Brasil e também no Estado de São Paulo, com mais de 45 mil pessoas, sendo uma das maiores etnias do Brasil em termos populacionais.
} 
ou em áreas mais acidentadas. Essa disposição está de acordo com uma autonomia e preponderância das famílias nucleares, que é articulada a relação de famílias extensas. Cada casal tem sua própria casa e é o responsável pela criação de seus filhos e de sua própria manutenção, mas conta com auxílios de parentes e da chefia. Famílias extensas, especialmente no caso de famílias tradicionais no local, ocupam uma mesma região da aldeia, ou um mesmo pátio, modelo de ocupação que segue uma tendência uxorilocal. Não raro, quando há espaço físico disponível na TI, eles também estabelecem núcleos um pouco mais afastados do centro da aldeia. As famílias extensas consistem também nos ambientes ao redor dos quais giram as articulações políticas das comunidades. Diferentemente de outros povos Jê, não há uma representação espacial clânica demarcada, prevalecendo a organização espacial por grupos de parentelas, que, à primeira vista, porém, pode parecer oculta. A clássica divisão exogâmica de metades kanhgág (VEIGA, $1994 ; 2000$ ) não tem hoje sua principal expressão ritual de outrora, o ritual do kiki. Mesmo sem ter feito um extensivo trabalho de levantamento do pertencimento às metades nas aldeias em que trabalhei, constatei haver casamentos na mesma metade, um desequilíbrio entre elas e poucos discursos que tinham a divisão por metades como aspecto explicativo êmico mais destacado para as diversas dimensões da sociabilidade aldeã. Mesmo assim, as metades continuavam sendo referência para casamentos ideais, especialmente no discurso de pessoas mais velhas.

Ao lado das metades, a caracterização entre índio (kanhgág), branco e mestiço é referência importante em termos de marcação de alteridade. A mestiçagem é presente como uma questão sociocósmica em todas as TIs da região. Em outro trabalho (CIMBALUK, 2013), destaquei o posicionamento nessa tríade índio/mestiço/branco, considerado no contexto de enunciação, havendo diferentes critérios e posições relativas a serem observadas em cada situação, não sendo a relação de filiação biológica em nossos termos ocidentais necessariamente o critério mais relevante. Ou seja, falar de alguém como branco, ou índio depende do contexto de interlocução e posição relacional. Assim, um indio puro, considerado em termos de seus conhecimentos antigos, pode passar a ver a si próprio como mestiço por estar em constante interlocução com o próprio antropólogo em língua estrangeira (português). O conhecimento e o uso da língua kanhgág pode ser um dos critérios nesse posicionamento, já que nem todos os índios e os mestiços da região são fluentes nela. A forma de relação para com os outros a partir dos idiomas do parentesco e da dádiva também pode prevalecer ao se considerar alguém como mestiço ${ }^{3}$.

Para além das aldeias nas Terras Indígenas, os indígenas também estão e circulam por toda a região, nas cidades e nas fazendas. Os empregos nas TIs, derivados de serviços públicos, projetos de compensação por empreendimentos, ou mesmo ocupações informais, acabam não dando suficientes alternativas econômicas aos índios, cujas terras agricultáveis são insuficientes e irregularmente distribuídas entre as famílias. Assim, indígenas são constantemente empregados nos sítios e fazendas ao redor das TIs, em trabalhos como de roçada, limpeza e colheita nas já raras plantações de café (em meio às vastas plantações

Existem diferenciações nativas ao avaliar comparativamente as diferentes Terras Indígenas, umas sendo eventualmente consideradas mais puras que outras com base em diferentes critérios. Existem também políticas matrimoniais específicas em contextos de maior presença de outras etnias, como é o caso da TI São Jerônimo, tema da dissertação de Spenasssatto (2016), o que não tratarei aqui. 
de soja e de aveia) e nas fazendas de gado de corte, ou em serviços esporádicos em locais mais distantes. Em outros casos, vão às cidades para trabalhar na construção civil, vender artesanato ou produtos extraídos de suas terras. Também outras situações diversas os levam às cidades, passando por apresentações culturais, reivindicações políticas e estudo em universidades, por exemplo.

Apesar de algumas das TIs estarem há vários quilômetros das cidades mais próximas, algumas das aldeias da região têm a presença constante de não indígenas e a relação com os regionais nesses casos é cotidiana, seja na aldeia ou nas cidades, seja em contextos de trabalho ou de descontração. Regionais vão trabalhar em serviços temporários de construção civil nessas aldeias ou na operação de máquinas agrícolas, por exemplo. Estes e outros, residentes em sítios dos arredores imediatos, vão às aldeias frequentar os bares ou os pequenos comércios indígenas, assim como indígenas frequentam bares e armazéns de não indígenas na região. Esses bares são um dos pontos onde podemos localizar os trajetos que envolvem a bagunça ou o bagunçar.

Iniciando, portanto, pelos bares, faço no próximo item uma descrição analítica da monogamia e da exclusividade sexual, abordando diferentes maneiras em que se colocam ao longo da vida e das gerações, delimitando aquilo que se pode entender como bagunça e as visões que a definem. Em seguida farei uma comparação com outros casos Jê-Bororo que trataram do tema, além de referenciais históricos sobre os Kaingang, dando destaque para as transformações ocorridas após a colonização não indígena. Trato ainda do caso das mulheres sem marido (mén tũ), casos que, comparados a outros de povos Jê-Bororo e junto à bagunça, indicam a possibilidade de abordagem como um período de vida não institucionalizado como um rito de passagem que precede ou se diferencia de comportamentos da vida adulta, mas que também compreende formas de contraefetuação da monogamia com exclusividade sexual.

\section{Bagunça em Oposição à Monogamia}

Os bares existentes em algumas das aldeias da região eram pequenos pontos de venda de bebidas e produtos alimentares diversos, com mesas de sinuca e aparelhos de som que ressoavam alto em partes dessas aldeias. Ali se reuniam indígenas e não indígenas para beber e jogar com seus parentes e amigos. Representavam, porém, para aqueles a quem se chamava de bagunceiros, apenas um ponto de passagem em um circuito mais amplo pela aldeia, havendo outros locais em que principalmente grupos de indígenas se reuniam para beber, conversar e paquerar durante a noite ${ }^{4}$.

A bagunça era caracterizada por alguns indígenas em algumas das TIs da região ao se referir a essa circulação noturna e diurna principalmente de pessoas mais jovens, envolvendo a bebida e o sexo real ou potencial sem seguir as restrições do casamento monogâmico. Era dita principalmente ao se observar essa circulação que indicava para

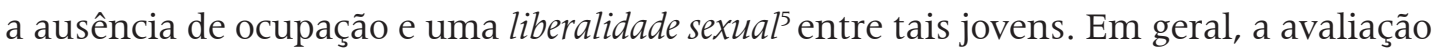

\footnotetext{
A discussão sobre a relação com não indígenas a partir dos bares e outros locais abordei em Cimbaluk (2020).

5 Entendendo esta ser uma expressão relativa, de cunho potencialmente moralizante, esclareço que estou utilizando aqui a expressão liberalidade sexual, buscando sintetizar alguns sentidos nativos daquilo que se contrapunha ao comportamento monogâmico com exclusividade sexual entre os parceiros.
} 
da bagunça ou daqueles que se dizia estarem bagunçando era relacionada a uma avaliação exterior, com carga negativa. Ela estava fundamentada não apenas em uma noção de monogamia mais ou menos duradoura defendida, mas também ao trabalho como forma de valor. Se a circulação diurna e noturna é seu aspecto mais visível e destacado, ela é também colocada em contraposição tanto ao respeito como ao ordenamento das relações entre famílias e os casamentos e a autoridade no interior destas. De outro lado, essa circulação se contrapõe ao trabalho como sustento para a família.

Para algumas pessoas nas aldeias, os kanhgág naquelas localidades já não respeitavam mais os outros, em especial seus cônjuges. Estariam vivendo em um estado de bagunça mais ou menos generalizada, em que os casamentos (monogâmicos) não representariam mais uma garantia de exclusividade sexual. Para essas pessoas então, se tornaria muito arriscado casar, pois certamente seriam traídas por seus cônjuges e teriam problemas decorrentes para criar seus filhos.

Essa visão da bagunça ou do bagunçar como algo contrário a um modo indígena de ser passado e original, é interessante notar, estava presente também e especialmente em Terra Indígena que era vista por indígenas kanhgág de outras TIs como sendo mais pura. Ou seja, se trata de uma visão que está colocada de maneira também relacional no que diz respeito a uma ideia de tradicionalidade. Se, de uma visão exterior, a tradicionalidade pode estar colocada para determinada TI, por sua vez, nessa TI pode haver posicionamentos que não reconhecem ali a tradicionalidade, podendo, inclusive, eventualmente identificá-la com espaços indígenas mais longínquos. Por outro lado, em outras perspectivas, noções de tradicionalidade postuladas, por exemplo, em torno do uso da língua kanhgág, podem não considerar a questão da sexualidade como elemento de avaliação nesse sentido, avaliando a liberalidade sexual maior em outra TI sem tocar na questão dos critérios de tradicionalidade.

Apesar da visão da bagunça como algo generalizado atualmente, conforme alguns indígenas de certas localidades, de um ponto de vista estatístico, poderíamos dizer que os casamentos monogâmicos mais ou menos estáveis predominavam na formação de casais kanhgág nos contextos estudados. Essa forma de união está, podemos dizer, na base das formas de construção de parentesco atuais. É a mais bem aceita. Tanto é assim que todos os papéis de destaque político têm como base homens casados, normalmente em uma relação estável por algum tempo ${ }^{6}$.

A chefia em cada Terra Indígena é composta pelo cacique, que é eleito e escolhe o vice-cacique e um conjunto de lideranças. Tanto a eleição como a composição das lideranças criam um ambiente político e também moral da chefia da comunidade e são momentos de muita expectativa e tensões entre parentelas da comunidade. Em geral, as lideranças são chefes de família, selecionados em diversas parentelas da aldeia, representando uma importante estratégia de composição de alianças entre as diferentes famílias extensas da comunidade. Importante para se evitar inclusive abertura de frentes faccionais. As lideranças têm função de intervenção em conflitos entre famílias e policiamento, por exemplo. Esses homens levam ao cacique os problemas ocorridos na aldeia, que são

6 Apenas muito recentemente algumas mulheres vêm assumindo postos de lideranças em algumas das comunidades em questão, sendo, porém, absoluta minoria. 
relatados a eles pelas famílias, e podem efetivamente prender pessoas da comunidade em cadeias existentes em cada comunidade.

O encarceramento em cadeias indígenas, assim como função de policiamento representado pelas lideranças, é algo comum em comunidades kanhgág, também em outras regiões, tendo sido incorporado principalmente a partir das atividades do Serviço de Proteção ao Índio (SPI) nessas áreas desde as primeiras décadas do século XX, que, juntamente ao histórico do contato, reforçou essa centralização e hierarquização da chefia, frequentemente expressa em cargos de nomenclatura militar. Atualmente, as lideranças também compõem um conjunto de deliberação conjunta com o cacique, com os quais há uma dinâmica de consultas para certas decisões sobre algumas questões concernentes à comunidade, variando em sua organização específica em cada localidade.

O cacique, o vice e as lideranças não devem beber, ou ao menos não excessivamente, e devem manter um comportamento de absoluto respeito aos demais. Como já colocado por Ramos (2008), o cacique seria como um exemplo de comportamento, devendo "andar certo na frente dos demais" ${ }^{\prime 7}$. Algo similar poderia ser colocado às lideranças, que também representam a garantia do respeito entre famílias. Usando o mesmo referencial, respeitar o cônjuge é andar certo com ele, expressando assim um comportamento sem erros, como podem ser considerados, por exemplo, os adultérios.

A bagunça é um ponto de tensão que a chefia tenta por vezes inibir. Em uma das comunidades, por exemplo, de tempos em tempos havia orientação pelo cacique para que as pessoas não ficassem circulando à noite pela aldeia e havia restrições para a venda de bebida nos dias de semana. Essa restrição era em especial para os que não tinham empregos na aldeia ou fora dela. Dizia-se que aqueles que andassem nesses dias à noite poderiam ser presos. Já em outra aldeia, criada há alguns anos, no início havia proibição total de circulação à noite, tentando justamente, entre outras coisas, promover uma outra moralidade em um novo espaço, no sentido de como se colocam as relações entre as famílias do local e como a chefia interfere nessas relações (CIMBALUK, 2013).

Outro âmbito em que a monogamia é evidenciada é o das igrejas. Na região há aldeias em que quase a metade dos habitantes é evangélica, havendo diversas denominações de igrejas em cada aldeia, a maioria delas com pastores ou obreiros indígenas. Os evangélicos condenam explicitamente os comportamentos sexuais que se afastam da monogamia com exclusividade sexual. Isso e a restrição à bebida alcoólica são elementos discursivos de diferenciação dos evangélicos em relação aos católicos. Muitos diziam, porém, que só pessoas com maior idade conseguiam seguir sendo evangélicos. Vários dos homens evangélicos narravam seus processos de conversão contrastando com períodos de juventude em que bebiam e bagunçavam muito.

A princípio, portanto, seguindo essas narrativas, poderíamos dizer que a bagunça ou o bagunçar seria algo característico da juventude, sendo um comportamento potencialmente avaliado como inadequado e cada vez mais repreensível quanto maior idade e a partir do momento em que a pessoa se casa e tem filhos. A partir de certo momento se passa então a ver seu próprio passado como de bagunceiro. O casamento estaria no próprio processo de tornar-se adulto, propiciando uma mudança de comportamento sexual, relacionado

Para discussão sobre a chefia e faccionalismo kanhgág, ver Fernandes (2003). Sobre a noção de respeito e sua relação com a política kanhgág ver Cimbaluk (2014). 
ao casamento e à noção de respeito ao cônjuge e aos parentes do esposo ou da esposa. A própria caracterização da bagunça teria, então, um sentido geracional do que poderíamos caracterizar como sendo o jovem, categoria que poderíamos ver delimitada especialmente pelo casamento, estabelecimento de uma residência e nascimento do primeiro filho.

Apesar de poder haver uma ideia de que os jovens contemporâneos seriam bagunceiros, isso deve, no entanto, ser relativizado. Há casos, por exemplo, de jovens evangélicos de segunda geração, ou seja, cujos pais se converteram e permaneceram na igreja. Alguns desses jovens casaram-se muito cedo, por vezes sem passar por uma fase de bagunça. Por outro lado, também havia exceções entre os adultos. Em alguns casos eram realizados os chamados bailes em casa, situações em que além de bebida, a liberalidade sexual parecia bastante irrestrita. Esses bailes eram por vezes promovidos por pessoas, mulheres ou homens casados (geralmente sem a presença do esposo ou esposa), contrariando frontalmente os parâmetros da monogamia, sendo algo bastante mais controverso que as próprias circulações noturnas dos mais jovens. Eventualmente, esses bailes eram promovidos por casados que estavam enfrentando crises momentâneas em seus casamentos, que podiam efetivamente se romper ou se manter. Esses bailes, que, em verdade, me pareciam bem mais raros e pontuais do que alguns discursos faziam ser, eram menos repreensíveis pela chefia, pois eram feitos dentro das casas, lugar da autoridade familiar.

Tais bailes contrastam com os bailes promovidos pela chefia ou por certas famílias, de caráter público e festivo, durante festas cívicas como na Semana do Índio ou outra festividade anual de cada comunidade, ou mesmo nas festas de santo promovidas por famílias católicas. Nesses eventos, onde se juntam parentes e afins para dançar, há outra dinâmica de relações que pode envolver também as relações maritais e sexuais. Eles também têm uma periferia, onde ficam alguns dos mais jovens e a partir de onde se pode ir a outros locais para eventuais relações sexuais. São também a partir de bailes assim que casais podem se formar.

Os casamentos, na maioria, não requerem grande cerimônia, podem ocorrer não muito tempo após a iniciação sexual, entre jovens de 15 ou 16 anos, e as relações sexuais os instituem. Tanto assim que, por vezes, certos interlocutores utilizam o termo casar com o sentido de ter relações sexuais, inclusive com algumas equivocações nas conversas com o pesquisador. Muitas vezes, o casamento, porém, é marcado pela fuga, quando o casal sai da aldeia por um tempo, sendo considerado o casamento efetivado quando há o retorno. O período de afastamento varia conforme a tensão da situação, podendo variar de um par de dias, meses, até anos. Quando é realizado sem fuga, em famílias mais tradicionais, pode haver aconselhamento pelos pais, pelo cacique e por outras lideranças. E esse aconselhamento pode significar que se instituiu formalmente o casamento. Em contextos de bagunça, porém, há casamentos fortuitos, que não são sequer comunicados à liderança, e que passam a ser um ponto de tensão para esta quando há problemas relativos às separações ou se os pais passam a se colocar contra a união, especialmente se não há fuga ou quando o casal é muito novo e não tem condições de se sustentar e manter as relações de prestação entre genro e sogro. Mas há casamento de jovens que perduram por algum tempo. Alguns sogros aceitam essas condições, não sem comentários 
entre outras famílias, tendo que se esforçar a ensinar (e fazer) seu genro a trabalhar, por exemplo, para construir uma nova casa.

Quando não há fuga e há aval dos chefes das duas famílias envolvidas, os noivos podem inclusive casar na igreja, com grande festa, especialmente se forem de famílias tradicionais da localidade e com grande status político na aldeia. A única cerimônia de casamento que pude acompanhar nesses moldes não apresentava características como as narradas por Paola Gibram (2016, p. 146) sobre a TI Rio da Várzea no Rio Grande do Sul, onde se evidenciava a oposição entre parentes como em guerra ritualizada. No entanto, poderia igualmente ser considerada um meio constitutivo de fazer política na comunidade, como forma de aliança entre grandes famílias, que, por vezes, mantinham política de intercasamentos por meio de gerações, como já identificara Fernandes (2003). Esse caso era especialmente interessante, pois os noivos já moravam juntos há algum tempo, e a cerimônia parecia muito mais uma ocasião de fortalecimento político em meio às complexas relações entre grupos políticos e famílias extensas na aldeia. Mas mesmo lideranças importantes e caciques não necessariamente tiveram casamentos assim ou mantiveram seus casamentos assim constituídos por toda a vida, ainda que em geral todos pertençam a famílias importantes em número e história em cada localidade.

Em relação às metades clânicas, a princípio apenas casamentos exogâmicos teriam o necessário grau de diferença no casal, para não se produzir um acúmulo de substâncias semelhantes e enfraquecimento dos descendentes (ROSA, 2011). No entanto, há situações variadas de como isso se coloca na prática. Em algumas comunidades, destaca-se inclusive a impossibilidade de seguir essa regra devido ao desequilíbrio demográfico entre as metades $^{8}$. Parece prevalecer, de qualquer forma, a vontade dos noivos na escolha do cônjuge, e oposições são superadas com fuga. Assim se criam casais de mesma marca, o que traz consequências sociológicas na comunidade e físicas aos descendentes, por exemplo, a baixa estatura.

Uma vez estabelecido o casamento, a tensão da relação monogâmica também é expressa em brigas de casais devido à infidelidade, gerando divórcios. É comum que o primeiro casamento de uma pessoa não passe de alguns anos ou até meses. Mesmo pessoas mais idosas tiveram vários casamentos durante a vida. Nesses casos de mudança de cônjuge, a fuga é um artifício frequente.

Há certamente muitas diferenças nas formas de relação dos casais, desde situações em que há maior cooperação e igualdade entre os cônjuges, com situações em que as mulheres podem se colocar como voz ativa na comunidade, até autoridades masculinas que buscam se mostrar como fortes e independentes, apesar de, mesmo nesses casos, eu ter verificado uma forte influência feminina indireta nas decisões do marido. Nesses últimos casos, porém, o homem pode querer se colocar como provedor exclusivo, até mesmo proibindo a mulher de fazer artesanato para vender ${ }^{9}$, de estudar fora da aldeia,

\footnotetext{
8 Este desequilíbrio pode estar associado a um reforço da patrilinearidade das marcas clânicas na região. Existem métodos de mudança de marca de uma pessoa, mas ele depende de especialistas rituais, e essa possibilidade não era destacada pela maioria de meus interlocutores.

9 A principal forma de artesanato produzido são os cestos de tiras de taquara trançados. A coleta da taquara é uma atividade masculina e a preparação do material e a confecção do cesto são atividades femininas. O produto é considerado da mulher, a ela cabe a venda do produto e dela é o dinheiro conseguido. Os maridos podem auxiliá-la nas viagens para a venda ou mesmo em certas etapas de preparação da fibra, mas em geral não interferem nem mesmo nas negociações para venda.
} 
podendo se contrapor à mulher eventualmente, mas esse tipo de situação é bem pouco frequente. Tais diferenças também se expressam em diversas formas de lidar com casos de adultério ou com o ciúme conjugal. Os conflitos entre os cônjuges e o/a respectivo/a amante podem exigir mediação de cacique e de lideranças, com soluções mais conciliadoras, mesmo que impliquem prisão de envolvidos. Mas há casos de violência com o parceiro ou o amante e fuga da vítima ou transferência do agressor para outras Terras Indígenas para evitar que ocorram tragédias. Há conflitos graves gerados em razão de ciúmes e de infidelidade, por vezes fatais. Em razão de situações de frustrações ou problemas mais sérios em relação a seus ex-companheiros, conheci mulheres que simplesmente tinham abandonado a perspectiva de se casarem novamente, passando a criar os filhos sozinhas, morando "sozinhas" após estarem todos casados, congregando alguns de seus genros eventualmente nas casas em torno da sua, ou, ao contrário, passando a morar próximo à casa de algum de seus genros.

Há que se destacar, porém, que nem sempre as relações extraconjugais implicam comprometimento de um casamento. Poderíamos dizer que, em alguns casos, ao menos um dos esposos passa por períodos mais ou menos extensos de maior liberalidade sexual com outros parceiros, sem que isso abale o casamento, mesmo esses casos sendo conhecidos na comunidade e comentados em fofocas. Monogamia e exclusividade sexual, portanto, são coisas que nem sempre estão colocadas como sinônimos. E se a monogamia está bastante incorporada como forma de casamento, a exclusividade sexual envolve muito mais dificuldade e conflitos. A noção de exclusividade sexual existe como associada ao casamento, mas nem sempre é efetiva. Isso gera tensões entre casais, fofocas e potenciais reprovações por meio das redes de parentesco da aldeia. Em casos que conheci, por exemplo, a aliança histórica entre grandes famílias e a importância da relação entre cunhados faziam com que o adultério pela esposa fosse relevado, ainda que passasse por outras intervenções. No caso de famílias evangélicas, esse comportamento era visto como influenciado por forças diabólicas, sendo feitas orações para o fim da influência maligna. Essas intervenções, mesmo que tenham um sentido cosmológico, trabalham também no sentido de manter casamentos e grandes alianças históricas. Isso, em todo caso, não isenta a família de constrangimentos, por vezes na própria igreja.

Sendo assim, ainda que possamos tratar o casamento monogâmico como uma referência de relação, que, em um plano sincrônico, pode se verificar predominante, vemos que há desafios e mudanças de casais no plano diacrônico a partir do momento em que a monogamia passa a significar também a exclusividade sexual dos cônjuges. Isso gera bastante tensão em certos casais, que passam a compor um histórico de relações entre as famílias na aldeia, até o ponto de ser necessário mudar-se para outra aldeia, mesmo que temporariamente. O caso se torna ainda mais difícil quando a questão envolve as próprias lideranças, caciques ou mesmo os pastores evangélicos, já que nesses casos se está contrariando o próprio exemplo que deveriam dar aos demais, sobre o qual reside boa parte de sua legitimidade para aconselhar ou manter presos os outros pelos mesmos motivos.

Se o cacique seria como o bastião do respeito na comunidade e o recurso por excelência utilizado para mediação dos conflitos, não é infrequente haver acusações de adultério sobre ele próprio, entrando em choque com a pressuposição de que ande certo, sendo um elemento crítico para sua destituição, usado politicamente nas disputas faccionais. 
O mesmo tipo de situação ocorre com outros atores que se colocam como exemplos de uma moral diante de parcelas da comunidade, os pastores ou obreiros evangélicos. Nesse caso, a acusação influi na trajetória religiosa dessas pessoas, que, por vezes, deixam a igreja ou perdem seu posto de destaque dentro dela. Praticamente todas as igrejas existentes nas aldeias em que trabalhei tinham passado por situações similares, sendo essa dinâmica um dos fatores que levavam a uma segmentação em diversas denominações evangélicas, influindo na composição de seus membros. Era também um dos argumentos utilizados por não evangélicos contra os evangélicos, por estes pregarem uma coisa e praticarem outra.

Existe uma dinâmica política, tanto no caso das lideranças como no caso dos pastores, que envolve a vantagem sexual (real ou pressuposta) e que entra em choque com uma ideia que essas próprias posições deveriam garantir, por meio do exemplo, para restringir e se contrapor à bagunça e, sobretudo, para garantir respeito entre as famílias. Com essa dinâmica, a posição daquele que deve dar o exemplo tenderia a levar a pessoa a negar o erro, passando a dar argumentos a potenciais opositores. No caso de lideranças, a noção de vantagem sexual pode se expressar fora da aldeia, em certos casos extraconjugais com indígenas ou não indígenas da região, ou mesmo com trabalhadoras do sexo, especialmente durante viagens a cidades distantes. Isso pode ou não ser tolerado pelas esposas, com conflitos mais ou menos abertos no casal. Sobretudo quando envolve outras indígenas casadas, porém, abre-se um caminho para disputas políticas latentes, pois isso rompe o respeito entre as famílias.

A dificuldade em manter um casamento e a exclusividade sexual, portanto, não pode ser tomada como algo exclusivamente juvenil. Não se trata tanto de uma oposição geracional, ainda que, por vezes, possa aparecer como tal. Adultos e casados também podem ser vistos como bagunceiros. As relações extramaritais e as trocas de esposos podem se tornar pontos de tensão entre famílias e ampliam uma visão de que o comportamento contemporâneo como um todo tenderia à bagunça. Essas trocas envolvem mudanças ou desafios para a manutenção de alianças entre famílias, ou afrontas ao cruzarem alianças e disputas políticas, gerando conflitos que podem também se somar às dinâmicas políticas comunitárias, como elemento constitutivo.

Para analisar o que podemos caracterizar como pontos de tensão, cabe analisar comparativamente com descrições de grupos Jê-Bororo entre os quais se colocam os Kaingang e também relatos históricos sobre essa etnia, buscando avaliar em que medida se colocam nessas tensões as transformações do grupo ao longo do tempo, com o contato com os não indígenas e a cristianização.

\section{Poligamia e Casamento em Contextos Jê-Bororo}

As questões da poligamia e do adultério são relatadas em vários trabalhos sobre grupos Jê-Bororo. Maybury-Lewis (1974, p. 87) aborda a poliginia como privilégio do chefe entre os Xavante. O adultério seria um problema apenas quando cometido por homem de outra facção. O autor fala ainda de casos de violência por homens a mulheres acusadas de adultério, mas acreditava que esses relatos seriam exagero dos narradores. Christopher Crocker (1985, p. 78) narra a existência entre os Bororo de casamentos que 
não teriam muita duração, chegando até um ano. Haveria naquele caso um predomínio da casa como corporação, baseada em compartilhamento de substâncias mais que em consanguinidade, tendo o casamento pouco peso institucional e de solidariedade. Vanessa Lea (1994; 1999), analisando os Mẽbengokre, indica a generalização da existência de amantes apesar da prerrogativa da monogamia. Também aponta para uma fase de juventude em que a liberalidade sexual seria bastante ampla. Os ciúmes sexuais seriam criticados, mas mesmo assim, eles provocariam agressões e divórcios. Algo similar é narrado por Crocker e Crocker (2009) sobre os Canela, uma sociedade guerreira em que o valor da generosidade é aplicado ao sexo, havendo situações tanto cerimoniais como cotidianas de práticas sexuais extraconjugais e também seriadas para ambos os sexos, apesar de não haver poligamia. Haveria nessa sociedade um período em que as mulheres seriam livres, podendo escolher seus maridos e trocá-los até conceberem seu primeiro filho. Brincadeiras e troças sobre sexo com parentes também eram comuns em um ambiente em que o sexo era vivido como alegria. No entanto, esses autores também chamam a atenção para transformações dessa sociedade, especialmente a partir da implantação de chefia autoritária não indígena do SPI na década de 1940 e também das mudanças impostas na organização econômica ao longo das décadas seguintes que levaram ao fim desse sistema, sendo priorizadas então as relações matrimoniais e o ciúme, e também inviabilizadas as cerimônias em que havia sexo seriado. Já entre os Laklanõ (Xokleng), vizinhos dos Kaingang no Brasil meridional, Jules Henry (1964), fazendo uma espécie de recomposição pretérita à década de 1930, reconheceu uma grande liberdade sexual e dos casamentos, com uma sexualização das crianças desde tenra idade e sem uma regra de fidelidade, com presença universalizada de amantes e de troca de esposos sem sérios conflitos. Havia tanto casos de poliginia como de poliandria e, até mesmo, casamentos conjuntos, sendo considerados pelo autor como acidentais, decorrentes da ausência de regras de casamento. Segundo Greg Urban, porém, eram regulados pelo sistema cognático, derivado do sistema de patrimetades (WIIK, 2004, p. 43). Isso contrasta com a caracterização de Flávio Wiik (2004), que, apesar de não tratar especificamente da exclusividade sexual dos casais, traz um contexto de casamentos monogâmicos compondo famílias extensas como corporações de parentesco social substancializado em uma comunidade que se converteu em massa ao pentecostalismo nos anos de 1950, que passa então a ser conformada por corporações de parentescos espirituais, substancializados (WIIK, 2004, p. 7).

De maneira sumária, ressalvadas as grandes diferenças temporais dos estudos, bem como o lugar do tema da sexualidade neles, podemos considerar que tais autores apontam diferentes contextos em que o adultério não é um problema em si e o casamento monogâmico com exclusividade sexual são elementos um tanto estranhos até pelo menos o primeiro quartel do século XX. Mesmo onde há tais prerrogativas, elas apresentam rupturas, havendo situações muito diversas em relação à importância da família nuclear e às formas de consanguinização nesse modelo, mas geralmente a família nuclear sendo menos significativa em relação a outras vinculações coletivas como clãs, metades e casas, ou mesmo as divisões faccionais.

Nos relatos sobre os Kaingang, isso também aparece, ainda que as trocas de esposos pareçam ter sido historicamente mais conflitivas, especialmente a partir das transformações do contato com os brancos, e que o pertencimento clânico e a exogamia de metades, 
descrita para o grupo desde as primeiras observações de Nimuendajú na década de 1910, possam estar lenta e progressivamente perdendo espaço no que tange à formação dos casais $^{10}$.

O contexto da colonização não indígena do Tibagi e de todo território Kaingang foi marcado por guerras com ampla resistência indígena e, de outro lado, por tentativas de aproximação a parcelas indígenas por meio de ações missionárias e colônias indígenas (MOTA, 2008; 2000). É preciso notar que os Kaingang da região do Tibagi tiveram contato com atividades missionárias desde o século XVII com a instalação das Missões Jesuíticas do Guairá na região do atual Estado do Paraná, ainda que tenha havido, ao que se sabe, uma influência mais indireta dessas missões, voltadas aos povos Guarani. Posteriormente, no século XIX, com missões Capuchinhas, a influência passou a ser direta, com aldeamentos com presença Guarani e Kaingang. No Tibagi, destacou-se o aldeamento São Pedro de Alcântara. Os religiosos Chagas Lima e Cemitille estiveram diretamente envolvidos nesse segundo momento. O Padre Francisco Chagas Lima, por exemplo, colocava em oposição de um lado a aparente boa vontade do chefe Hyppolito Condoi em aceitar o batismo em 1812, e, de outro, ser polígamo e supersticioso. O religioso ainda expressa a devassidão e os costumes bárbaros em que viviam os índios nos campos de Guarapuava (LIMA, 1842) na Região Centro-Sul do Paraná. O Frei Cemitille (TAUNAY, 1888, p. 260) relata o costume de mudança de casamentos devido às exigências do pai da esposa e também quando a mulher ficava velha, casando as moças, portanto, várias vezes. A poliginia seria característica de homens que se destacavam na guerra ou na caça, podendo ter três ou mais mulheres, sendo chamados Tremani, valente, forte. Diz que em caso de o marido surrar a mulher ou algum filho, apartar-se-ia o casal sem cerimônia e o homem procuraria outra esposa. De maneira muito similar a Lima, o Frei relata a poligamia como motivo de sarcasmo do capitão indígena Manoel Aropquimbe, quando o capuchinho tenta convencê-lo a largar suas quatro mulheres, ficando com apenas uma (TAUNAY, 1888, p. 267).

Telêmaco Borba (1908, p. 11), que sucedeu os religiosos com uma direção laica do Aldeamento São Jerônimo até sua extinção, no início do século XX, descreveu a poliginia entre os Kaingang da bacia do Tibagi. Segundo ele, um indivíduo podia ter entre quatro a seis mulheres, geralmente da mesma família, com preferência para casamento com a filha das irmãs. As filhas dos irmãos seriam consideradas como suas, ou seja, tínhamos um princípio de patrilinearidade e exogamia operante. Apesar de os homens dificilmente abandonarem as esposas, as mulheres facilmente deixavam os maridos, unindo-se a outros, fugindo por alguns dias no mato. Se os amantes fossem encontrados pelo marido abandonado, este poderia dar uma surra no outro homem, retornando a mulher ao lar que abandonara. Os casamentos também implicavam uxorilocalidade e prestação de serviços do genro ao sogro.

No século XX, além da presença das igrejas nas TIs, a ação intensificada do Estado Brasileiro por meio do SPI e, posteriormente, da FUNAI, no sentido de civilizar e de integrar o índio à sociedade envolvente, dessa vez, em uma perspectiva laica, também funcionaram como repressoras de práticas não cristãs. Procurou-se substituir festas tradicionais, como

${ }_{10}$ O que não significa necessariamente uma mudança cosmológica nos mesmos termos. 
o kiki, em que as marcas clânicas e exogâmicas eram performadas e quando, segundo Veiga (2000, p. 227), era comum roubar a mulher do outro. Essas festas tradicionais foram substituídas por festas cívicas, reprimindo concepções de famílias não cristãs, além de serem introduzidas formas de trabalho forçado e o já mencionado sistema repressivo, com funções de policiamento e cadeias. As transformações ao longo da colonização, com a intensificação no século XX, modificaram amplamente a vida kaingang, como nota Tommasino (1995). Faz inclusive com que os indígenas mais velhos identifiquem um tempo antigo e presente diferenciados, marcados por diversas composições ambientais, espaciais e sociais (TOMMASINO, 1995, p. 272).

Já dentro dessa nova condição de aldeamentos sob direção do SPI, Dr. Geraldo de Paula Souza (1918, p. 745) visitou acampamentos kaingang de localidade entre os rios Feio e Peixe (São Paulo). O autor destaca a instituição familiar sobre a da chefia suprema, observando que mulheres eram amarradas ao rancho do homem até querer segui-lo. Mesmo nesse contexto, Paula Souza nota a poligamia, sendo a bigamia bem comum, apesar de as mulheres, no contato com civilizados, quererem estabelecer a monogamia. Cita até mesmo um possível caso de suicídio por uma mulher que seria adepta da monogamia, matando-se pelos desgostos do ciúme ${ }^{11}$.

Em Toldo das Lontras (Palmas), no sudoeste paranaense, Baldus (1979 [1937]) constatou em 1933 que, além de monógamos, eles diziam sempre ter sido assim, havendo também abstinência antes do casamento. No entanto, se os homens lhe pareceram fiéis, as mulheres entregavam-se eventualmente aos brancos por "terem pênis maiores", o que era feito, porém, apenas com brancos conhecidos e estimados, sendo-lhes fiéis. Os maridos não se queixavam disso, exigiam apenas a simpatia do branco. Apesar de a mulher ser indiferente no coito, sujeitando-se aos desejos do marido, o autor indica uma relação igualitária em geral entre marido e mulher, sem maus-tratos e com auxílio dos homens nas atividades femininas.

Várias décadas mais tarde, também entre kanhgág paulistas da região mencionada antes, Delvair Melatti (1976, p. 34; 91) relatou que as regras exogâmicas, consideradas desde as publicações de Nimuendajú (1993 [1913]) e Baldus (1979 [1937]), praticamente não eram seguidas. A autora observava lá o interesse em integrar-se à sociedade regional, recorrendo-se aos casamentos interétnicos, especialmente pelas mulheres. Melatti (1976) retoma na bibliografia a existência de casamentos arranjados, nos quais as mulheres, por vezes, usavam técnicas contraceptivas ou abortivas para não dar à luz ao filho de marido forçado. No entanto, em seu campo, identificou haver maior liberalidade quanto aos casamentos e as experiências sexuais na juventude, inclusive de mulheres com os homens civilizados da região, o que era em geral reprovado pelos pais. As mulheres tinham muito ciúmes de seus maridos, sendo motivo de rixas frequentes, e os adultérios eram os principais motivos de hostilidades nas aldeias, com casos de assassinatos, inclusive.

Com a chegada das igrejas evangélicas históricas e depois as pentecostais, com criação de novas igrejas ou instalação delas nas comunidades, a repressão ganha outro caráter, com a distinção entre convertidos e não convertidos, e diferenciações feitas com base nas condutas pessoais (VEIGA, 2004, p.184).

\footnotetext{
${ }^{11}$ Casos de suicídio entre kanhgág não são comuns. Os que soube, reconhecidos como tais, pareciam ter relação com situações conjugais.
} 
Pode-se ver que houve mudanças significativas em relação ao casamento, com a repressão, a poligamia, que mesmo assim parece prática muito custosa a desaparecer. De outro lado, ao menos no contexto do Tibagi contemporâneo, não se soube de relatos de casamentos forçados nos moldes mencionados. No entanto, vemos que agressões decorrentes de adultérios eram presentes mesmo quando a poligamia era colocada, ainda que já em um contexto de transformações intensas vividas pelos grupos mencionados. Se inicialmente a poliginia era vista como uma marca da coragem e habilidade, para guerra e caça, passa progressivamente a haver uma pressão social para adoção da monogamia. Pressão não indígena, mas também visivelmente indígena, pelo menos a partir da intensificação do contato. Isso faz também com que eventuais casamentos polígamos, mesmo que ainda existentes, sejam ocultados dos não indígenas. Foi grande minha surpresa ao ficar sabendo por interlocutora indígena, após meu período de campo, que existia um homem casado com duas irmãs em uma das comunidades em que estudei. Ou seja, ainda existe essa possibilidade, mesmo que estando colocada agora em um lugar social subalterno. Esses casamentos podem ser considerados raríssimos e podem ser quase tão surpreendentes para outros indígenas quanto para nós, ou, ao contrário, não serem comentados.

Em campo, falando sobre essas possibilidades com um interlocutor de meia idade, ele, além de confirmar que os antigos tinham várias mulheres, disse ser comum que a iniciação sexual masculina se desse com a mulher do irmão mais velho, com consentimento ou incentivo deste, e que mesmo sua avó lhe teria dito que isso não era mais assim, pois os índios haviam aprendido o jeito dos brancos. Agora, se descobrissem um adultério, matavam os amantes.

Reforça-se que as relações com os cunhados de sexo oposto eram e são privilegiadas assim como relações destacadas no passado com filhas da irmã. Mas não é possível generalizar que sejam atualmente aceitas quando assim colocadas, podendo gerar tensos conflitos familiares quando um cunhado, por exemplo, tem relações sexuais extraconjugais com a cunhada, mesmo que ela seja solteira. A ponto de gerar rupturas de alguma das mulheres com seus parentes, algo emocional e estruturalmente grave para ambos os lados, considerando-se a uxorilocalidade e a manutenção pressuposta dos vínculos da mulher com seus parentes mesmo após o casamento.

De outro lado, os ciúmes conjugais, assim como podem gerar violência para com o parceiro ou adúltero, com casos de assassinatos ou tentativas de assassinato, podem ser também repreendidos por parentes dos envolvidos ou lideranças. Assim ouvi um caso de um homem que, enciumado de sua esposa adúltera e tendo a agredido, foi amarrado pelos irmãos da mulher, que a casaram com o outro homem (pai do senhor que narrou a história).

Com a proximidade progressiva aos não indígenas a partir do século XX, quando se intensifica o processo de colonização e de cerceamento territorial das comunidades na região, e a intensificação do trabalho indigenista, a liberalidade sexual passa a ser também uma questão, gerando tensões entre pais e filhos, mas há casos de deliberada procura 
por casamentos fora da comunidade, assim como apontava Melatti e como nos casos de experimentações sexuais com não indígenas regionais por jovens ${ }^{12}$.

Trabalhos como os de Veiga (1994) e Fernandes (2003) apresentam tentativas em algumas comunidades de reprimir o adultério, com cadeia ou tronco ${ }^{13}$, mas nem assim eliminando a recorrência de tal prática. Com o modelo de chefia centralizada, fortalecida no próprio processo de contato, se abriram tais possibilidades de repressão em outros níveis. Mas ela sempre depende muito do histórico das comunidades e, nos casos práticos, da relação entre os envolvidos e deles com o cacique e sua família. A tensão existente é indicada com o adultério colocado como principal motivo das hostilidades, como apontava Melatti (1976). Almeida (2004, p. 238), ao identificar a associação entre a bagunça e o consumo alcoólico, aponta que era reconhecido entre seus interlocutores que o consumo de bebida alcoólica e as brigas entre casais eram os principais motivos de prisões. De outro lado, Veiga (2000, p. 104) explicita visão de que o adultério seria algo natural ao menos na perspectiva masculina para os homens, já que, como lhe disse certo cacique, um homem só não iria com uma mulher disponivel se fosse capado.

Nesse sentido, uma noção que pode ser associada à dificuldade de se seguir o respeito entre as famílias é a noção de aproveitar. Especialmente a partir de perspectivas masculinas ouvi essa noção referindo-se a uma espécie de consideração da disponibilidade sexual de outros, homens ou mulheres. Especialmente em contextos de bagunça, nas circulações ou festas noturnas envoltas em bebidas alcoólicas, ou quando havia algum tipo de encontro a sós com este outro, especialmente se este outro era solteiro ou solteira.

Da mesma forma, existem casos de repressão a casamentos que não seguem a regra exogâmica de metades, com a prisão temporária dos esposos, como no caso de Palmas analisado por Fernandes (2003). Isso, porém, desconheço ocorrer na região do Tibagi. Fernandes coloca inclusive a tendência de havaianização, com a terminologia de parentesco pelo parâmetro de metades ser sobreposta pela terminologia da parentela como unidade de consanguíneos, incorporando termos do português. De minha experiência no Tibagi, percebi que ambas as terminologias coexistem, apesar da importação de termos em português, sendo utilizadas em diferentes momentos da vida social, mas prevalecendo no cotidiano a segunda, e, por vezes, a primeira sendo até colocada como algo do passado, a depender do contexto de interlocução.

O contexto que tratamos, portanto, parece ser mais difundido entre as comunidades kanhgág, apesar de existirem variações bastante grandes entre Terras Indígenas. O grau de liberalidade das práticas sexuais em cada comunidade varia muito, tanto entre indígenas e especialmente em relação ao estrangeiro. Assim como a eventual contraposição a isso por meio de tentativas de imposição de regras comunitárias mais estritas, visando à manutenção da fidelidade e à restrição à bebida em alguns casos por meio de chefias ou de igrejas, com intuito de criar uma moralização aos moldes cristãos e nacionais, e o respeito entre famílias. É também um ponto importante de tensão quando envolve contextos faccionais, podendo se tornar elemento politicamente relevante nestes.

\footnotetext{
12 Discuto tais casos em Cimbaluk (2020).

13 Assim como a cadeia, o tronco, instrumento de prisão e tortura é tido como tradicional, apesar de sua história estar ligada também ao contato. Seu uso, porém, é muito pouco comum atualmente nas diversas comunidades kanhgág, não sendo utilizado nas comunidades do Tibagi ao que soube, a não ser como recurso retórico.
} 


\section{Mén Tũ e Casos de Violência Sexual}

A bagunça, no entanto, não deve ser vista necessariamente como algo característico dos últimos tempos, ainda que sua categorização assim pejorativa possa sê-lo. Assim como os casos de poligamia, são relatadas na bibliografia Jê as posições de mulheres que não se casam e que possuem uma posição institucionalizada, inclusive servindo ao sexo seriado em determinadas situações. Temos, por exemplo, relações cerimonializadas no caso das me-kuprú, as moças de pátio, que Da Matta (1976) registra entre os Apinayé. Lá se tratava de uma posição institucionalizada na qual a moça poderia optar, contando a moça com dois guardiães para sua proteção. No caso Canela, como expõem Crocker e Crocker (2009), havia mulheres nomeadas para o sexo seriado em festivais, para ter relações com homens membros de determinada classe ritual. Naquele caso também, não ceder sexualmente ao outro poderia ser caracterizado como sovinagem e ter consequências para o indivíduo na comunidade e levar eventualmente ao sexo seriado não consentido. Já McCallum (1994) aborda casos ritualizados do Alto Xingu que, segundo a autora, seriam relacionados à fertilidade, ou seja, à própria possibilidade de reprodução da comunidade.

Entre os Kaingang, Veiga (2000, p. 104) já chamava a atenção para as chamadas mbédtũu, mulheres sem marido, que teriam relações sexuais por meio de pagamentos. Essas mulheres já existiriam mesmo antes da intensificação do contato, segundo a autora. Recentemente, Paola Gibram (2016) também tratou de mulheres mén tũ, que seriam as mulheres que, no contexto de agressividade masculina com complacência da liderança, teriam optado por não se casar. Essa opção as colocaria como mulheres sem parentes, levando à perda da marca clânica e da condição de incesto considerada a partir da regra exogâmica. Dessa maneira, o incesto, que teria caráter de animalidade, seria superado. Tais mulheres levariam a acirramento de tensões e ciúmes das mulheres casadas. No entanto, como chama a atenção a autora a partir de sua própria situação em campo em comparação com outras mulheres, havia as mén tũ que tinham my'a, vergonha, o que remete justamente à atitude de respeito em relações de afinidade e, especificamente, em relação a não saírem para beber entre os homens e a não andarem à noite pela aldeia.

O fato de as mén tũ não terem parentes, como coloca a autora, permite analisar perspectivas masculinas que observei, propiciando que essas mulheres sejam consideradas sem guardiães, o que facilitaria as investidas masculinas. De certa maneira, autoriza-se, na perspectiva masculina, que se tenha, seja com moças ou rapazes, relações sexuais não consensuais ou, muito mais frequentemente, pela troca por bebida, como referi antes, destacando o termo aproveitar. Os guardiães das mulheres solteiras, por assim dizer, deveriam ser seus pais, que, além de prevenirem a ocorrência de abusos contra elas, poderiam agir em diferentes esferas no caso de ser avaliada a ação como agressão, seja por meio das lideranças, do cacique e, eventualmente, até pelos agentes externos à comunidade.

Como me relatou uma colega antropóloga, havia comentários entre os kanhgág sobre práticas de sexo seriado denominadas puxirão, em metáfora à prática de trabalho coletivo nas roças ${ }^{14}$. Algo bastante similar me foi descrito por um homem, envolvendo sua própria iniciação sexual. Essas situações não necessariamente seriam consensuais, 14 Puxirão são práticas mormente agrícolas, mas também de outros serviços, com caráter coletivo que são tidas como
"tradicionais". 
ponto, por vezes, ambíguo nas narrativas masculinas que ouvi. Havia também discursos sobre certos cacicados em que essas situações seriam mais frequentes, pois as lideranças não tomavam providências quanto aos casos ocorridos. Esse podia ser um ponto de crítica a esses cacicados, usados também retoricamente nos embates políticos.

Eventualmente alguns casos, envolvendo casais ou grupos, são chamados pelos próprios indígenas como estupros. Os casos pareciam, por vezes, ser tratados com certa conivência pelas lideranças da comunidade, em especial aqueles casos envolvendo rapazes ou em famílias marginais às relações políticas da aldeia ${ }^{15}$. Entravam também nos discursos políticos faccionais. Já para outros interlocutores, parecia haver uma relação evidente entre a posição sexual feminina (tanto de homens como de mulheres) e o fato de beberem junto com homens heterossexuais nas andanças noturnas como um legitimador, uma causa para a efetivação dessas práticas, representando uma disponibilidade expressa no termo aproveitar. Por vezes, porém, casos envolvendo famílias bem posicionadas na política local e em oposições faccionais à chefia podem ser levados inclusive a instâncias não indígenas (FUNAI, Polícia Civil), gerando processos judiciais e prisões. Nesses casos dependendo fundamentalmente da iniciativa dos parentes da vítima.

Colocar-se como mulher de respeito, como destacou Gibram (2016), portanto, é fundamental para que se consiga estabelecer-se como mulher independente não disponível sexualmente de tal maneira. Já adiantei que em alguns casos as mulheres teriam optado por não casar novamente justamente pelo contexto de seus relacionamentos anteriores. Algumas, com filhos, mantinham essa posição de solteira sem maiores problemas, considerando-se que eram mais velhas. Isso não significava que não mantivessem relações sexuais eventuais, em relações com maior ou menor permanência. Em alguns desses casos, tais mulheres, constituindo unidade político-familiar, inclusive, tinham voz política bastante ativa e influente em suas aldeias. No entanto, no caso das moças, isso era uma situação muito tensa especialmente conforme a família à qual pertencia a pessoa.

A disponibilidade sexual, ressalto, era colocada muito mais em relação ao contexto de bagunça, associada à bebida e à circulação noturna. Isso tanto para mulheres solteiras como para jovens rapazes. Mesmo nesses contextos, o respeito é também associado às famílias. Pois a posição e a relação entre as famílias influenciavam na forma de comportamento e no que se fala para o outro.

O status de uma família na comunidade é algo complexo e não pode ser resumido apenas ao seguimento ou não da regra exogâmica de metades em sua conformação ou sua posição política ou tradicionalidade no local. Há algumas famílias em que os próprios pais bagunçam, ou seja, mesmo adultos e casados, bebem, circulam à noite e mantêm relações sexuais com terceiros.

Mesmo com mulheres casadas há situações que parecem se aproximar ao sexo seriado e cujo consentimento é algo difícil de averiguar, já que esse ponto não era destacado pelas narrativas masculinas que eu escutava ${ }^{16}$, como foi o caso de uma mulher sobre a

\footnotetext{
15 Isto é, considerando as relações políticas centrais, envolvendo as principais famílias e facções em uma determinada aldeia, aquelas que disputam o poder centralizado e constituem grupos de poder com lideranças ou oposições. Isso não quer dizer que tais famílias marginais não façam política a seu modo.

16 Levando em consideração também que a noção de vontade e consentimento é muito mais uma leitura a partir de uma visão ocidental laica como elemento central à sexualidade e pessoa. Como vimos em outros casos, a generosidade sexual pode ser elemento mais importante.
} 
qual um homem me contou ter sido pega na estrada, teve suas roupas rasgadas e teve relações sexuais com vários homens. Tanto ela não delatou os agressores como seu marido supostamente não teria ficado sequer sabendo de nada.

Em outras duas situações que conheci, quase todos os filhos e especialmente filhas do casal eram bagunceiras. Assim, algumas famílias parecem se tornar um ambiente propício para que tais comportamentos se generalizem e entrem na vida adulta, provocando uma espécie de consenso sobre tal posição a partir da recorrência dos fatos envolvendo aquela família ou seus filhos. Mas há outras situações em que a situação familiar não justificaria tal caracterização, sendo também a posição da própria pessoa diante dos demais fundamental. Isso é válido tanto para os casos em que filhos de casais que estabeleceram relações monogâmicas estáveis quanto para filhos de lideranças da comunidade que se mantinham na bagunça mesmo após casados.

Sendo assim, aqueles que são ou deveriam ser os guardiães das moças e rapazes também estão em questão ao se relacionarem com estes últimos. Suas histórias e posições na comunidade também se colocam nessas avaliações.

Em alguns casos os próprios pais podem não considerar que seus filhos estejam nesse caminho, podendo até se ofender com tais afirmativas. Era o caso, por exemplo, de um pai que ameaçava cortar a orelha do suposto amante de sua filha, casal que a liderança considerava favorecer estabelecer casamento. Dessa forma também, a perspectiva pode até se inverter em detrimento dos homens bagunceiros, pois como me disse tal pai, ele não iria querer que uma filha sua (considerada por outros como bagunceira por já ter engravidado mais de uma vez sem efetivar nenhum casamento) casasse com um homem que já casara muitas vezes e que não trabalhava. De forma similar, considerava que um homem que casasse com uma mulher que engravidara do cunhado não andaria certo com ela por isso. Sendo assim, a própria biografia da pessoa pode levar a determinado tipo de relação para com ela posteriormente, para além de suas vinculações de parentesco. Nesse contexto, a liderança mesmo pode intervir para fazer com que bagunceiros que estejam andando juntos se casem, ou para que casais que andam bagunçando parem com tais práticas. Nesses casos, pode ser usada a ameaça ou a efetiva prisão. Em outras situações, pelo contrário, a família expulsou temporariamente a moça bagunceira de casa, o que, do meu ponto de vista, só favorecia a bagunça.

É preciso destacar também, como já mencionado, que, a partir de perspectivas evangélicas indígenas, esses comportamentos podem ser derivados de influência demoníaca, do diabo, nén kórég (coisa ruim). De outro lado, outros interlocutores associaram tais comportamentos a espíritos considerados maus, jagrẽ kórég sendo estes colocados ou como constitutivos da pessoa, ou como espíritos não constituintes dela, mas que a influenciariam, como espécie de guias maléficos, que eram atraídos pelo seu comportamento errático, reforçando essa ideia. Até mesmo a feitiçaria era uma causa possível aos comportamentos de bagunceiros, algo já apontado também por Veiga (2000, p. 145) ${ }^{17}$.

Vemos, então, que mesmo as formas tradicionais de alternativas ao casamento podem gerar tensões e conflitos, eventualmente gerando violência sexual ou entre cônjuges, estando também relacionadas a composições cósmicas diversas, envolvendo

\footnotetext{
17 Sobre tentativas de solução de casos de feitiçaria, neste sentido, ver Cimbaluk (2019).
} 
a própria consideração da composição da pessoa. Essas situações, que dificultam uma leitura apenas pelo idioma da generosidade sexual, envolvem também relações sociais mais complexas na dinâmica das aldeias, em que o parentesco se coloca como elemento fundamental juntamente com a chefia e seu papel de repressão e de manutenção do respeito, destacando os erros e repreendendo estes. E, além disso, o histórico de comportamentos e de relações da família e sua posição política no contexto comunitário também são elementos relevantes.

\section{Considerações Finais}

Aproximando-nos um pouco da análise de Da Matta ou de Crocker e Crocker (2009), poderíamos sugerir que o período de bagunça ou do bagunçar seria como uma fase de rito de passagem, mas, nesse caso, sem uma estrutura institucionalizada, que só pode ser considerada como período distinto para termos analíticos. Ou seja, seria um período em que certa liberalidade é pressuposta, mas que, nesse caso, não tem uma marca clara de coletivização, ou de início e término. É mais ou menos aceita, quando não incentivada por uns, ao passo que outros a reprovam, podendo influenciar seus filhos a saltarem tal passagem. Ela é mais reprovável a partir do momento em que já se tenha filhos, especialmente para as mulheres. As relações de parentesco e a chefia e lideranças de cada localidade atuam como elementos de regulação e mediação envolvidos. Procurando resolver conflitos ou mesmo buscando meios de que as tensões sejam amenizadas por meio de uma maior penalização dos bagunceiros.

A bagunça, longe de necessariamente ser apenas algo contemporâneo, parece ser um momento historicamente importante na trajetória pessoal e familiar. É nesse momento em que múltiplas configurações, testes e formações de novos casais e famílias se dão na comunidade. Sem a certeza de que essas alianças possam dar certo ao longo do tempo, ou mesmo que sejam pensadas em termos de longo prazo e conformação de grandes alianças.

A bagunça e o bagunçar é um momento e um comportamento que homens e mulheres de maior idade também já passaram e, por vezes, custaram a sair ou a deixá-lo e, eventualmente, retornam a ele, configurando uma possibilidade de contraefetuação da monogamia e da exclusividade sexual associada a ela por meio, sobretudo, da cristianização e do contato com os não indígenas. Em alguns casos, a bagunça é levada para o restante da vida, talvez nem sempre por uma opção clara da pessoa, mas por uma conjuntura social e cósmica que acaba por dificultar a criação de laços mais estáveis mesmo em idade mais avançada. Em outros casos, momentos de maior liberalidade sexual podem existir mesmo entre casais. A não institucionalização dessa fase e, pelo contrário, as pressões em prol da monogamia e da exclusividade sexual favorecem situações de desacordo e polêmica. De forma similar, as trocas de cônjuges podem ser tensas e requerer fuga dos amantes para evitar conflitos maiores. Os ciúmes conjugais, porém, não são algo recente, apesar de a poligamia ter sido no passado algo representativo de valor. As transformações históricas nas formas de casamento mais aceitas atualmente, porém, parecem acentuar as tensões. 
Para além das tensões nas famílias e entre as famílias na aldeia, então, essas tensões podem resultar em repressões a partir da chefia e das lideranças. Pelo contrário, quando as lideranças passam a não resolver essas tensões e os conflitos se acumulam, ou quando envolvem as próprias lideranças, os casos amorosos supostos ou efetivos passam a compor o jogo de disputas políticas das aldeias.

\section{Referências}

ALMEIDA, Ledson Kurtz de. Análise Antropológica das Igrejas Cristãs entre os Kaingang: Baseada na Etnografia, na Cosmologia e no Dualismo. 2004. 278p. Tese (Doutorado em Antropologia Social) - Universidade Federal de Santa Catarina, Florianópolis, 2004.

BALDUS, Herbert. O culto aos mortos entre os Kaingang de Palmas. In: BALDUS, Herbert. (org.). Ensaios de etnologia brasileira. São Paulo; Brasília, DF: Companhia Editora Nacional; INL, [1937] 1979. p. 8-33.

BORBA, Telêmaco. Actualidade indígena. Curitiba: Impressora Paranaense, 1908.

CIMBALUK, Lucas. A Criação da Aldeia Água Branca na Terra Indígena Kaingang

Apucaraninha: política interna, moralidade e cultura. 2013. 250p. Dissertação (Mestrado em Antropologia Social) - Universidade Federal do Paraná, Curitiba, 2013.

CIMBALUK, Lucas. Respeito e reciprocidade: referenciais da moralidade Kaingang.

Mediações, Londrina, v. 19, n. 2, p. 146-163, jul.-dez, 2014.

CIMBALUK, Lucas. Sexualidades kanhgág e algumas de suas potencialidades no domínio da afinidade potencial. Campos, [s.l.], v. 21, n. 1, jan.-jun. 2020. Disponível em: http://dx.doi. org/10.5380/cra.v2lil.73917. Acesso em: 19 nov. 2020.

CIMBALUK, Lucas. Xamanismos kanhgág: as artes de Pedro Chapéu Branco. Espaço Ameríndio, Porto Alegre, v. 13, n. 2, jul.-dez. p. 211-241, 2019.

CROCKER, Christopher. Vital Souls: Bororo Cosmology, Natural Symbolism, and Shamanism. Tucson: University of Arizona Press, 1985.

CROCKER, William H.; CROCKER, Jean G. Os Canela: parentesco, ritual e sexo em uma tribo da Chapada Maranhense. Rio de Janeiro: Museu do Índio, 2009.

DA MATTA, Roberto. Um mundo dividido: a estrutura social dos índios Apinayé. Petrópolis: Vozes, 1976.

FERNANDES, Ricardo Cid. Política e parentesco entre os Kaingang. 2003. 288p. Tese (Doutorado em Antropologia) - Universidade de São Paulo, São Paulo, 2003.

GIBRAM, Paola Andrade. Penhkár: política, parentesco e outras histórias kaingang. Curitiba: Appris; Florianópolis: Instituto Nacional de Pesquisa Brasil Plural, 2016.

HENRY, Jules. Jungle people: a Kaingang tribe of the highlands of Brazil. New York: Vintage Books, 1964.

LEA, Vanessa. Desnaturalizando gênero na sociedade Mẽbengokre. Estudos Feministas, [s.l.], ano 7, n. l e 2, p. 176-194, 1999. Disponível em: https://periodicos.ufsc.br/index.php/ref/ article/view/11991. Acesso em: 12 jun. 2017.

LEA, Vanessa. Gênero feminino Mebengokre (Kayapó): desvelando representações desgastadas. Cadernos Pagu, [s.l.], n. 3, p. 85-115, 1994. Disponível em: https://periodicos. sbu.unicamp.br/ojs/index.php/cadpagu/article/view/1724. Acesso em: 12. jun. 2017. 
LIMA, Francisco das Chagas. Memória sobre o descobrimento e colônia de Guarapuava. Revista Trimensal de História e Geographia ou Jornal do Instituto Histórico e Geographico Brasileiro, Rio de Janeiro: Typographia de João Ignacio da Silva, Tomo IV, n. 13, p. 43-64, 1842 .

MAYBURY-LEWIS, David. Akwẽ-Shavante Society. New York: Oxford University Press, [1967] 1974.

MCCALLUM, Cecilia. Ritual and the origin of sexuality in the Alto Xingu. In: HARVEY, Penelope; GOW, Peter (ed.). Sex and Violence: Issues in representation and experience. London; New York: Routledge, 1994. p. 90-114.

MELATTI, Delvair Montagner. Aspectos da organização social dos Kaingang paulistas. Brasília: Funai, DGPC, 1976.

MOTA, Lúcio Tadeu. As colônias indígenas no Paraná provincial. Curitiba: Aos quatro ventos, 2000.

MOTA, Lúcio Tadeu. As guerras dos índios Kaingang: a história épica dos índios Kaingang no Paraná (1769-1924). Maringá: Editora da Universidade Estadual de Maringá, 2008.

NIMUENDAJÚ, Curt. Etnografia e indigenismo: sobre os Kaingang, os Ofaié- Xavante e os índios do Pará. Campinas: Ed. da UNICAMP, [1913] 1993.

PAULA SOUZA, Geraldo. Notas sobre uma visita a acampamentos de índios caingangs. Revista do Museu Paulista. São Paulo: Typ. do Diário Official, 1918. (tomo X)

RAMOS, Luciana Maria de Moura. Vénh Jykré e Ke Há Han Ke: Permanência e Mudança do Sistema Jurídico dos Kaingang no Tibagi. 2008. 255p. Tese (Doutorado em Antropologia Social) - Universidade de Brasília, Brasília, 2008.

ROSA, Patrícia Carvalho. Para deixar crescer e existir: sobre a produção de corpos e pessoas kaingang. 2011. 186p. Dissertação (Mestrado em Antropologia Social) - Universidade de Brasília, Brasília, 2011.

SPENASSATTO, Josiéli Andréa. Os dois lados da mistura: desafios da coabitação e dos intercasamentos na Terra Indígena São Jerônimo (PR/Brasil). 2016. 203p. Dissertação (Mestrado em Antropologia Social) - Universidade Federal de Santa Catarina, Curitiba, 2016.

TAUNAY, Alfredo d'Escragnolle. Os indios Caingangs (Coroados de Guarapuava): Monographia acompanhada de um vocabulario do dialecto de que usam. Revista Trimensal do Instituto Historico e Geographico Brazileiro, Rio de Janeiro: Typographia de Pinheiro \& C, suplemento ao tomo LI, 251-310, 1888.

TOMMASINO, Kimiye. A história dos Kaingang da bacia do Tibagi: uma sociedade Jê Meridional em Movimento. 1995. 351p. Tese (Doutorado em Antropologia) - Universidade de São Paulo, São Paulo, 1995.

VEIGA, Juracilda. Cosmologia e práticas rituais Kaingang. 2000. 304p. Tese (Doutorado em Antropologia Social) - Universidade Estadual de Campinas, Campinas, 2000.

VEIGA, Juracilda. Organização Social e Cosmovisão Kaingang: uma introdução ao parentesco, casamento e nominação em uma sociedade Jê Meridional. 1994. 221p. Dissertação (Mestrado em Antropologia Social) - Universidade Estadual de Campinas, Campinas, 1994.

VEIGA, Juracilda. Religiões Cristãs entre os Kaingang: mudança e permanência. In: WRIGHT, Robin M. (org.). Transformando os Deuses: igrejas evangélicas, pentecostais e neopentecostais entre os povos indígenas no Brasil. Campinas: Editora da Unicamp, 2004. p. 169-198.

WIIK, Flávio Braune. Christianity converted: an ethnographic analysis of the xokleng Laklanõ indians and the transformations resulting from their encounter with pentecostalism. 2004. 364p. Dissertation (Doctor of Philosophy) - University of Chicago, Chicago, 2004. 


\section{Lucas Cimbaluk}

Doutor em Antropologia Social pela Universidade Federal de Santa Catarina. É antropólogo do Instituto do Patrimônio Histórico e Artístico Nacional (IPHAN).

Endereço profissional: Praça Getúlio Vargas, n. 268, Florianópolis, SC. CEP: 88020-030.

E-mail: lucas.cimbaluk@gmail.com

ORCID: https://orcid.org/0000-0002-5183-0341

\section{Como referenciar este artigo:}

CIMBALUK, Lucas. Bagunça: casamentos e sexualidade em tensão entre indígenas kanhgág. Ilha - Revista de Antropologia, Florianópolis, v. 23, n. 2, p. 73-94, maio, 2021. 